\title{
The association between the initial outcomes of COVID-19 and the human development index: An ecological study
}

\author{
Mohamed Buheji ${ }^{\mathrm{a}}$, Amer AlDerazi ${ }^{\mathrm{b}}$, Dunya, Ahmed ${ }^{\mathrm{a}, \mathrm{c}, *}$, Nicola Luigi Bragazzi $^{\mathrm{d}, \mathrm{e}}$, \\ Haitham Jahrami ${ }^{\text {b,f }}$, Randah R. Hamadeh ${ }^{\mathrm{f}}$ and Ahmed S. BaHammam ${ }^{\mathrm{g}, \mathrm{h}}$ \\ a International Institute of Inspiration Economy, Bahrain \\ ${ }^{\mathrm{b}}$ Ministry of Health, Bahrain \\ ${ }^{\mathrm{c}}$ Social Science Department, University of Bahrain, Zallaq, Bahrain \\ ${ }^{\mathrm{d}}$ Laboratory for Industrial and Applied Mathematics, Department of Mathematics and Statistics, York University, \\ Toronto, ON, Canada \\ ${ }^{\mathrm{e}}$ Department of Health Sciences, School of Public Health, University of Genoa, Genoa, Italy \\ ${ }^{\mathrm{f}}$ College of Medicine and Medical Sciences, Arabian Gulf University, Manama, Bahrain \\ ${ }^{\mathrm{g}}$ Department of Medicine, College of Medicine, University Respiratory and Sleep Disorders Centre, King Saud \\ University, Riyadh, Saudi Arabia \\ ${ }^{\mathrm{h}}$ The Strategic Technologies Program of the National Plan for Sciences and Technology and Innovation in the \\ Kingdom of Saudi Arabia, Riyadh, Saudi Arabia
}

Received 15 May 2021

Accepted 24 November 2021

\begin{abstract}
.
BACKGROUND \& OBJECTIVE: Outcomes of the pandemic COVID-19 varied from one country to another. We aimed to describe the association between the global recovery and mortality rates of COVID-19 cases in different countries and the Human Development Index (HDI) as a socioeconomic indicator.

METHODS: A correlational (ecological) study design is used. The analysis used data from 173 countries. Poisson regression models were applied to study the relationship between HDI and pandemic recovery and mortality rates, adjusting for country median age and country male to female sex ratio.

RESULTS: During the first three months, the global pooled recovery rate was $32.4 \%$ (95\% CI $32.3 \%-32.5 \%$ ), and the pooled mortality rate was $6.95 \%(95 \% \mathrm{CI} 6.94 \%-6.99 \%)$. Regression models revealed that HDI was positively associated with recovery $\beta=1.37, p=0.016$. HDI was also positively associated with the mortality outcome $\beta=1.79, p=0.016$.

CONCLUSIONS: Our findings imply that the positive association between the HDI and recovery rates is reflective of the pandemics' preparedness. The positive association between the HDI and mortality rates points to vulnerabilities in approaches to tackle health crises. It is critical to better understand the connection between nations' socioeconomic factors and their readiness for future pandemics in order to strengthen public health policies.
\end{abstract}

Keywords: COVID-19, pandemic, ecological studies, correlational studies, HDI, mortality, socioeconomic determinants

\footnotetext{
*Corresponding author: Dunya Ahmed, International Institute of Inspiration Economy; and Social Science Department, University of Bahrain, Zallaq, Bahrain. E-mails: dunya@inspiration economy.org; Dr.dunya@hotmail.com.
} 


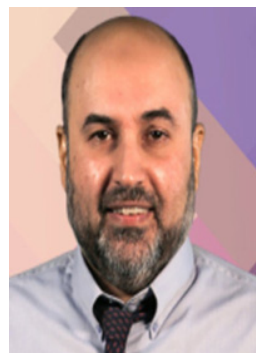

Dr. Mohamed Buheji is the founder of International Inspiration Economy Project which includes International Institutes of Inspirational Economy and Youth Economy Forums. His focus lies on the areas of Excellence, Knowledge, Innovation, Inspiration, Change Management, Enhancement of Competitiveness, Future Foresight, Socio-economic problem solving, Power of Thinking, Lifelong Learning Curiosity and Poverty Economy. Besides being a retired professor from Bahrain University, Dr. Buheji is also the Founder of the International Journal of Inspiration \& Resilience Economy and International Journal of Youth Economy. Dr. Buheji has published since 2008 more than 200 peer-reviewed journals, conferences papers, and 29 books https:// www.researchgate.net/profile/Mohamed_Buheji/publications.

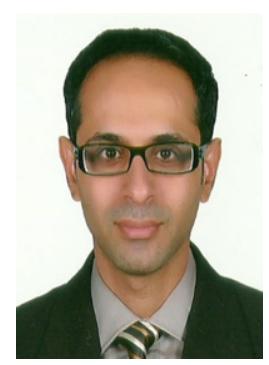

Dr. AlDerazi is a senior consultant (general surgeon) in the Salmaniya Medical Complex, Bahrain. He graduated from the University of Alexandria, Egypt. His clinical fellowship in General Surgery was in McMaster University, Canada.

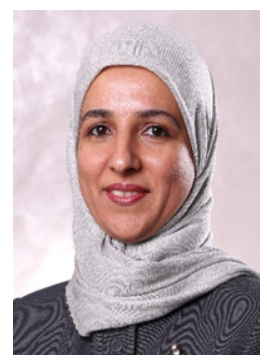

Dr. Dunya Ahmed is co-founder of International Inspiration Economy Project, an assistant professor in University of Bahrain \& Scientific Committee Chairperson in the Institute of Inspiration Economy, EU \& MENA, in addition to being Strategic Planning \& Development Adviser in Supreme Council for Women. She Completed her $\mathrm{PhD}$ in social work at the University of Warwick, specialized and concentrated mainly on equity and the rights of women and people with disabilities. She is cofounder of Inspiration Economy concept, Journals, projects \& institutions globally. She is an Editorial Board member of several international scientific journals and an active member of several NGOs, as well as the Chairperson of Inspiration Economy Society in Bahrain. She has also contributed to the preparation and implementation of a number of strategies and preparation and discussion of international reports.

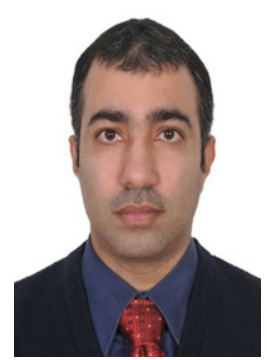

Haitham Jahrami is the Chief, Rehabilitation Services at Governmental Hospitals, Ministry of Health, Kingdom of Bahrain. He is also an Associate Professor at the Department of Psychiatry, College of Medicine and Medical Sciences, Arabian Gulf University, Kingdom of Bahrain. Research active staff with approximately 200 papers, Dr Jahrami attained his $\mathrm{PhD}$ from University of Ulster, UK, in 2006.

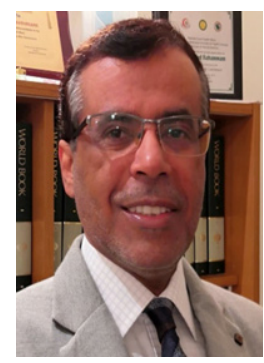

Professor Ahmed S. BaHammam 's research focuses on several sleeprelated topics, including obesity hypoventilation syndrome, central hypersomnolence disorders, and the impact of intermittent fasting and mealtime on sleep and circadian rhythm. He has received several grants for his research. Prof. BaHammam is the Executive Director of Academic Affairs at the Medical City, King Saud University, Director of Prince Naif Health Research Center, Director of the University Sleep Research Center, and former Director of the Research Ethics Council at the College of Medicine, King Saud University.

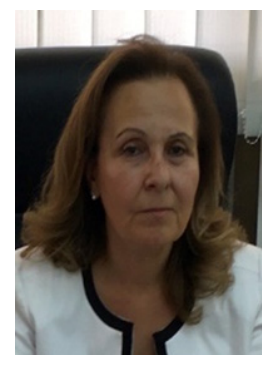

Dr. Randah Ribhi Hamadeh is a professor of community medicine and currently works as a consultant to the Dean, College of Medicine and Medical Sciences (CMMS), Arabian Gulf University (AGU), Bahrain. She served as the Vice Dean for Graduate Studies and Research from 2010-2020 at CMMS, AGU and chaired the Department of Family and Community Medicine from 2005-2010 and was acting chair during 2016-2017. Dr. Hamadeh attained both her BSc in Environmental Health and MSc in Epidemiology from the American University of Beirut and the $\mathrm{PhD}$ in Community Medicine from the University of Oxford, UK.

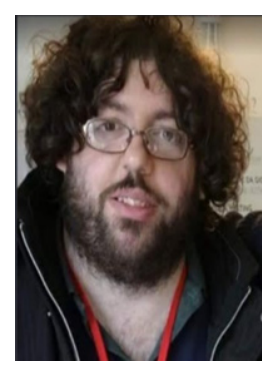

Dr. Nicola Luigi Bragazzi is a biomathematician and biophysicist $\mathrm{He}$ got his Medical Degree in general medicine and surgery from Genoa University (Genoa, Italy) in 2011, $\mathrm{PhD}$ in biophysics from Marburg University (Marburg, Germany) in 2014, and specialization in Public Health from Genoa University (Genoa, Italy) in 2017. $\mathrm{He}$ is a member of the Cochrane Association (Cochrane Reviewer) for the Cochrane Epilepsy Group. Currently working on infectious diseases (including COVID-19) and vaccination modelling and big data mining in biomedicine at York University, Toronto, ON, Canada.

\section{Abbreviations:}

$\begin{array}{ll}\text { WHO } & \text { World Health Organization } \\ \text { COVID-19 } & \begin{array}{l}\text { coronavirus disease 2019 } \\ \text { Public Health Emergency of } \\ \text { PHEIC }\end{array} \\ \text { International Concern } \\ \text { GDP } & \begin{array}{l}\text { Gross Domestic Product } \\ \text { HCI }\end{array} \\ \text { Human Capital Index } \\ \text { DGHED } & \begin{array}{l}\text { Domestic General Government Health } \\ \text { Expenditure }\end{array} \\ \text { HDI } & \text { The Human Development Index } \\ \text { BCG } & \text { Bacillus Calmette-Guérin }\end{array}$




\section{Introduction}

On 30 January 2020, the World Health Organization (WHO) declared coronavirus disease 2019 (COVID-19), a Public Health Emergency of International Concern (PHEIC), and on 11 March 2020, as a pandemic [1]. COVID-19 pandemic can be viewed beyond a global health problem; it can be regarded as a global human developmental crisis that affects socio-economic development of nations [2]. The pandemic is much more than a worldwide public health emergency; it is a universal human development crisis, reflecting our interaction with the ecosystem we are part of [3]. The continuation of this unprecedented global emergency affected many essential aspects of life and among the groups affected: families, youth, women, and students where many things had to be changed in their life $[4,5]$.

There are substantial variations between countries when it comes to COVID-19 detection and mortality rates, which appear to be highest in the United States and lowest in some Asian countries [4]. These variations exist even within different regions of individual countries [6]. Numerous authors have provided possible explanations for these variations, which ranged from individual-related factors (age, gender, race, ethnicity, smoking status, presence of chronic lung disease, and level of vitamin D3 or its supplementation), [7-15] environmental measures (temperature, humidity, level of pollution and ultraviolet radiation) [16-22] or country factors (population density, population mobility, geographical location in the form of latitude and timing or type of country-based mitigation measures such as testing) [23-32].

The socioeconomic approaches of assessing the associations between a country's development and the epidemiology of COVID-19 are very scarce, particularly for outcomes of infections. Data derived from recent and historical studies on previous pandemics, including the influenza pandemics in 1918 and 2009, suggest that country-level socioeconomic factors can affect detection rates and clinical outcomes [33-35]. Accordingly, factors such as the age of the population, race, affluence, inequality, poverty, unemployment, insurance, or access to healthcare may account for these between-country or betweenregion variations [36]. Buja et al. (2020) identified several socioeconomic factors (rates of employment and public transportation usage) associated with significant differences in the rate of COVID-19 spread in 36 provinces of Northern Italy [37]. A similar publication identified other socioeconomic factors (age distribution, male to female ratio, and lowincome) associated with significant differences in the number of detected COVID-19 cases in 177 neighbourhoods in New York City [38]. A study from the United Kingdom implicated the in-house density as the source of variation [39]. These publications examined individual socioeconomic factors in isolation and did not scrutinize the effect of several socioeconomic factors together. Furthermore, they investigated the association with the COVID-19 detection rate and did not consider clinical outcomes such as recovery and mortality rates. Further, a publication from Brazil evaluated the effect of several socioeconomic variables on COVID-19 exponential growth-phase infection and mortality rates across 36 countries. It demonstrated no associations with the Gross Domestic Product (GDP) per capita, Human Capital Index (HCI), or Domestic General Government Health Expenditure (GGHED) per capita [40]. This contradicts the findings of an American study that collected COVID-19 pandemic infection data and social-ecological data of 178 countries and found that the GDP per capita was significantly positively associated with cumulative mortality rates of COVID-19 [41].

The Human Development Index (HDI) is a composite marker of life expectancy, education, and per capita income indicators, which are utilized to classify countries into four tiers of human development $[42,43]$. The psychometric properties of this measurement tool have been published [44]. The focus of HDI is to measure average achievements in human development in a society and is often used by countries as part of their long-term national strategic planning [45]. It has several components, such as life expectancy at birth, mean years of schooling; and, gross national income per capita. HDI is used to determine the relationship between the socioeconomic development of countries and the incidence of diseases. Several studies have examined the association between the HDI and the epidemiology of both communicable and non-communicable diseases, but none has focused on the epidemiology of COVID-19 [46].

Identifying socioeconomic variables associated with COVID-19 is vital for public health systems to guide mitigation strategies to improve health outcomes in a given area as part of ongoing global efforts to contain the pandemic and to drive future approaches that may tackle the possible resurgence of the disease $[6,37]$. 
The objectives of this study were to describe the association between global recovery and mortality rates of COVID-19 cases and the HDI in different countries, attempt to explain the variation betweencountries and determine the association between the global recovery and mortality rates of COVID-19 cases, and the HDI in different countries after adjusting for age and sex during the first three months of declaring it as a PHEIC.

\section{Methods}

\subsection{Study design}

A correlational (ecological) study design. The unit of analysis was the country. The study design served to make inferences about the ecological effects of HDI status on country-level mortality and recovery rates. It is not our intention to make inferences about the biological effects on individual disease risks [47, 48]. It permits performing comparisons using available country-level secondary data that may not be feasible to obtain at the individual-lever with the available time and resources.

\subsection{Data sources}

A total of 173 countries were included in the analyses. Inclusion criteria were: 1) the country has an HDI value for the year 2019 published in the Human Development Report (HDR)/United Nations [49], and 2) the country has secondary data on the COVID-19 pandemic, which include the total number of COVID-19 cases, number of recovered COVID-19 cases, number of deaths from COVID-19 and made available at world meter: coronavirus live update [50]. Secondary data on the median age and sex ratio per country were obtained from the United Nations Department of Economics and Social Affairs [51].

For each country, the global recovery rate and global death rate were calculated by dividing the number of recovered/dead cases by the total number of reported COVID-19 cases. For modelling, the log transformation of the number of recoveries and the number of deaths was made. All data were accessed on 2 May 2020.

\subsection{Data analyses}

Poisson regression analysis models were used to study the association between COVID-19 outcome rates and HDI and to adjust for demographics (median age and male: female ratio) and countrylevel parameters. The following model for the number of observed recovered cases and the number of observed deaths was used: $\left(\mu_{\mathrm{c}}\right)$ to COVID-19 virus was specified: $\log \left(\mu_{c}\right)=\beta 0+\beta 1^{*} \mathrm{HDI}+\beta 2^{*}$ median age $+\beta 3^{*}$ male to female ratio $+u_{c}$. In the equation, c stands for the country.

We repeated the analyses stratifying for the HDI rank categories; the following were used: very high, high, medium, and low human development.

All regression estimates and corresponding 95\% confidence intervals (CI) and $p$-values were reported. The level of significance was considered less than 0.05 . All data were analysed using Stata software version 16.1 (StataCorp, College Station, TX, USA). The Poisson model was fitted via the Poisson command.

Poisson regression is a type of regression analysis that uses a generalized linear model to describe count data and contingency tables. The response variable $\mathrm{Y}$ is assumed to have a Poisson distribution, and the logarithm of its anticipated value may be described by a linear combination of unknown factors in Poisson regression. When used to model contingency tables, a Poisson regression model is also known as a loglinear model [52].

\section{Results}

Within the first three months of the pandemic, there were about 3.5 million cases, with 1.1 million recoveries and approximately 250 thousand deaths. The global recovery rate was $32.4 \%$ (95\% CI $32.3 \%-$ $32.5 \%$ ) and global mortality rate was $6.95 \%(95 \% \mathrm{CI}$ $6.94 \%-6.99 \%)$.

Table 1 presents the associations between the global outcomes of COVID-19 and HDI. A total of 168 countries were analysed for the recovery rate and 152 for the mortality rate. Poisson regression models revealed that HDI was positively associated with the $\log$ recovery rate after adjusting for age and sex $\beta=1.37, p=0.016$. HDI was also positively associated with the log mortality rate after adjusting for age and $\operatorname{sex} \beta=1.79, p=0.016$.

After stratifying for the HDI rank categories, there were data from 61/62 (98.5\%) countries from the very high human development, 49/55 (89\%) countries from high human development, 29/37 (78.5\%) countries from the medium human development, and 34/36 (94.5\%) countries from low human development. 
Table 1

The association between the outcomes of COVID-19 and HDI

\begin{tabular}{lccccccc}
\hline Variable & \multicolumn{3}{c}{ COVID-19 Recovery Rate } & & \multicolumn{3}{c}{ COVID-19 Mortality Rate } \\
\cline { 2 - 3 } & $\beta$ & $95 \% \mathrm{CI}$ & $p$-value & & $\beta$ & $95 \% \mathrm{CI}$ & $p$-value \\
\hline HDI & 1.37 & $0.25-2.49$ & $0.016^{*}$ & & 1.79 & $-0.02-0.09$ & $0.016^{*}$ \\
Intercept & -0.33 & $-0.95-0.29$ & 0.30 & & -0.84 & $-1.77-0.08$ & 0.08 \\
\hline
\end{tabular}

*Significant at 0.05 adjusting for median age and sex ratio.

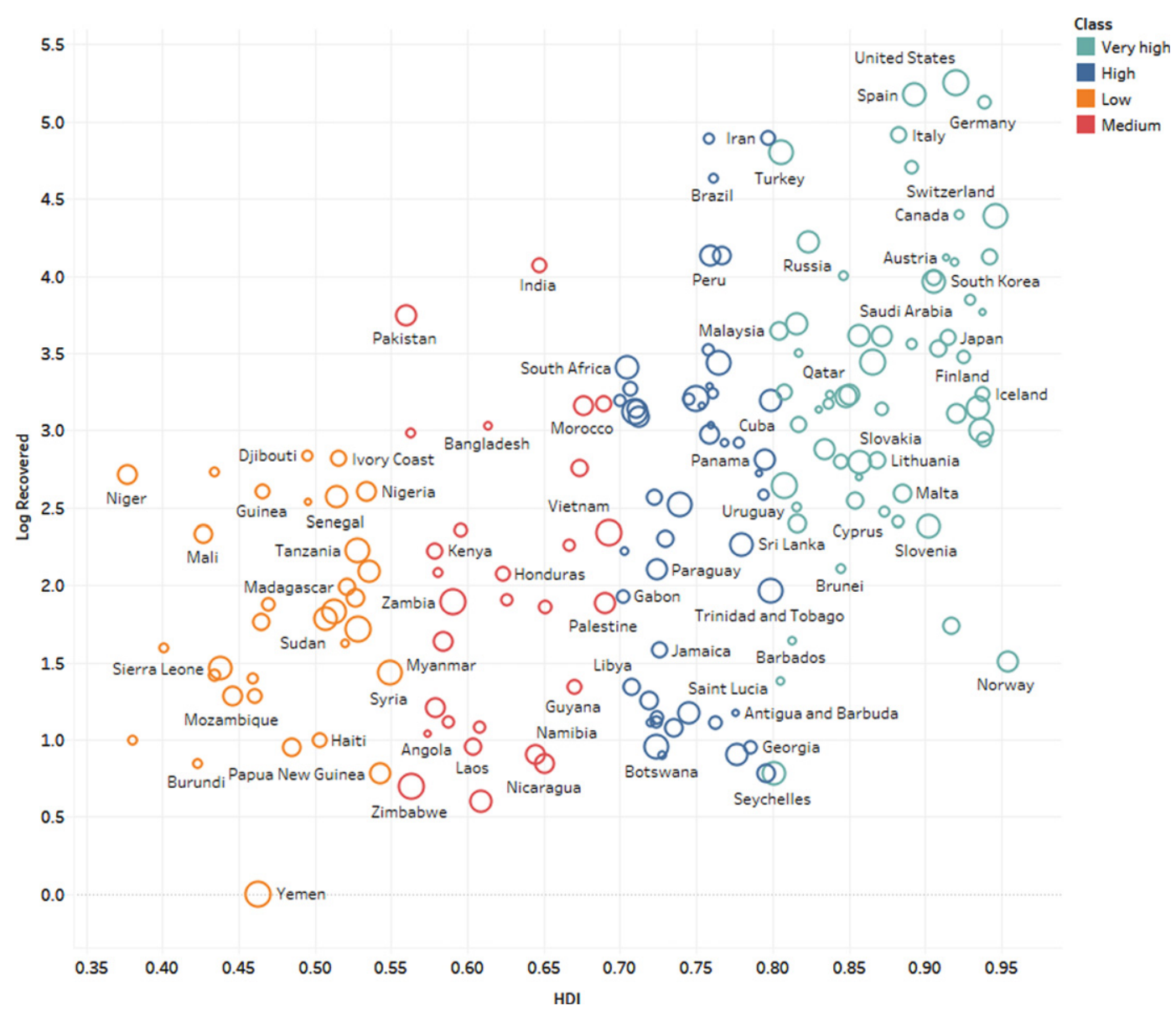

Fig. 1. The COVID-19 recovery rates by HDI classes.

Figure 1 graphically depicts the association between the COVID-19 recovery rate and HDI, and Figure 2 portrays the association between the COVID-19 mortality rate and HDI. For very high human development, the pooled recovery rate and the pooled mortality rate were $29.1 \%$ and $7.3 \%$, respectively. The pooled recovery rate and pooled mortality rate were $52.8 \%$ and $5.5 \%$, respectively, for countries with high human development. The corresponding values for the medium human development were
$32.3 \%$ and $2.9 \%$, respectively, and for those with low human development $27.2 \%$ and $2.9 \%$, respectively.

Table 2 presents the distribution by the HDI classification of COVID-19 recoveries, COVID-19 deaths, all-cause deaths, and total population. Very high HDI countries represent $16.2 \%$ of the world population, and their share in expected deaths from all causes is 18.6\%; however, their share in COVID-19 deaths was $87.7 \%$ at the time of the study. 


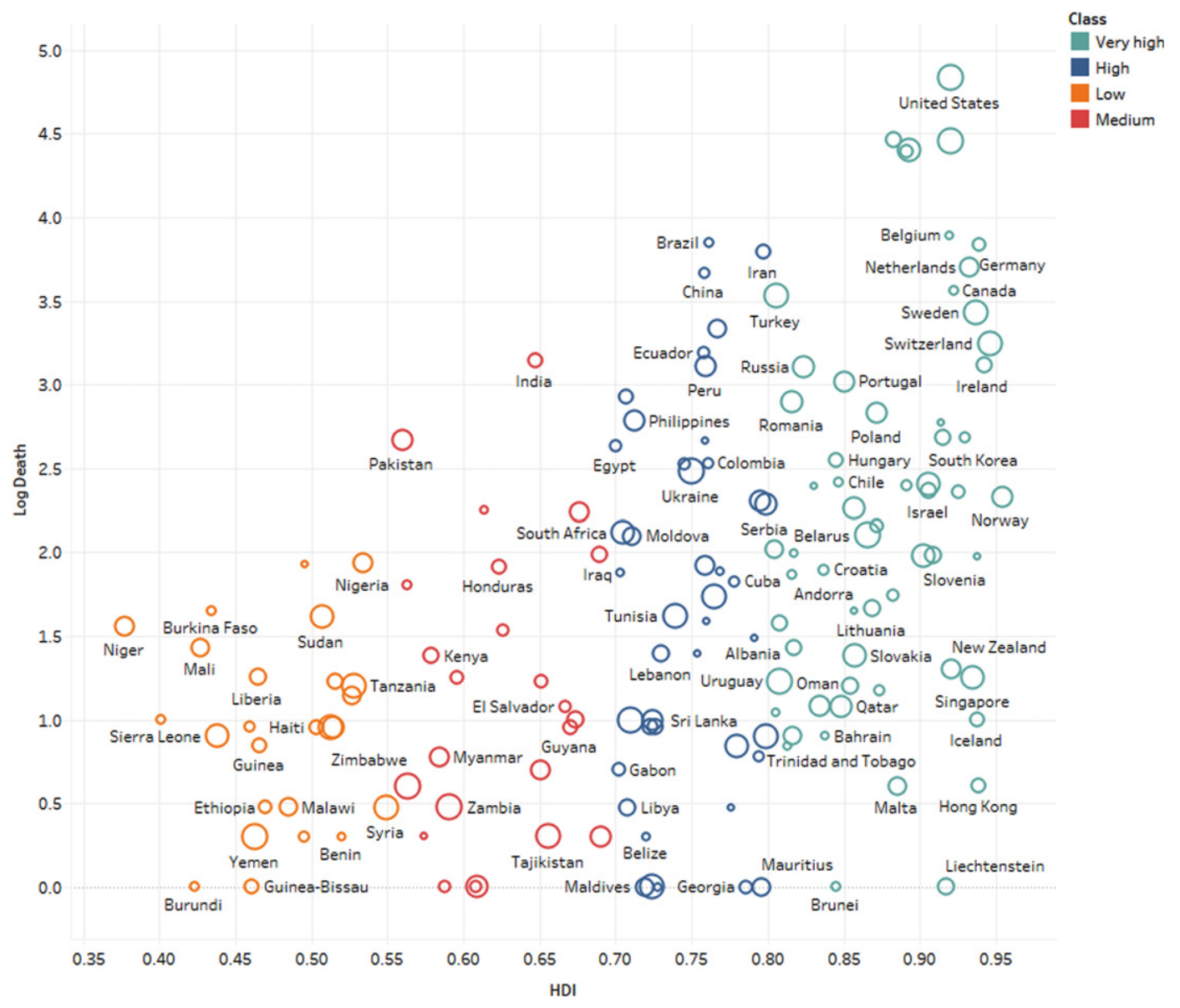

Fig. 2. The COVID-19 mortality rate and HDI classes.

Table 2

Distribution by human development index classification: COVID-19 recoveries, COVID-19 deaths, all-cause deaths and total population (percent)

\begin{tabular}{lcccc}
\hline & $\begin{array}{c}\text { Share in } \\
\text { COVID-19 } \\
\text { recoveries }\end{array}$ & $\begin{array}{c}\text { Share in } \\
\text { COVID-19 } \\
\text { deaths }\end{array}$ & $\begin{array}{c}\text { Share in } \\
\text { expected } \\
\text { deaths } \\
\text { from all } \\
\text { causes }\end{array}$ & $\begin{array}{c}\text { Share in } \\
\text { world } \\
\text { population }\end{array}$ \\
\hline Very high HDI & 75.0 & 87.7 & 18.6 & 16.2 \\
High HDI & 22.5 & 11.1 & 32.7 & 34.1 \\
Medium HDI & 2.1 & 1.0 & 38.3 & 39.7 \\
Low HDI & 0.4 & 0.2 & 10.6 & 10.0 \\
\hline
\end{tabular}

Note: Data until 2 May 2020. Deaths from all causes extrapolated to 2020 with the 2016 crude mortality rate. COVID-19 data is reported for 173 countries, shares to all-cause deaths, and the total population include all countries of the world.

\section{Discussion}

The World Health Organization has laid forth a timeline of pandemic stages. Interpandemic, "alert, pandemic, and transition are the four phases [53]. The stages of the pandemic risk assessment coincide with the phases of the continuum. The three steps of the risk assessment are preparedness, response, and recovery.

In this study, we attempted to assess the potential country-level determinants of COVID-19 recovery and mortality rates and explain the between-country variations assuming reasonably that surveillance systems and reporting fatalities were accurate and comparable. Our findings imply a significant positive association between the HDI and both the recovery and mortality rates.

It is expected that countries with a lower HDI will claim a high share of COVID-19 mortality [40, 54-56]. A high proportion of the urban population in 
countries with a lower HDI live in high-density areas such as slums, favelas, and camps where associated restrictions against personal freedom or primary economic needs (e.g., gaining access to food or water) may prove a potentially severe humanitarian crisis following exposure to an epidemic [54, 57]. Therefore, flattening the curve on COVID-19 may prove to be more difficult, resulting in higher case fatality. Moreover, health systems in low-income countries that face severe constraints in normal times regarding staffing and medical equipment are unlikely to possess the capacity to cope with the surge in demand, especially for those needing respiratory support [58, 59]. However, our data suggest that the mortality rate was higher in countries with a higher HDI.

Countries will have to make difficult decisions in the future. Individual responses to guidance on how to best avoid transmission will be as essential, if not more so, than official initiatives [60].

Although many aspects of the COVID-19 infection remain uncertain, it has been demonstrated that mortality trends are higher in older populations and males $[14,61-63]$. The higher death rates from COVID-19 deaths in high-income counties were explained by the higher proportions of elderly populations [64]. However, in this report, we corrected both age and sex to account for these potential confounders. Moreover, developing countries with a lower HDI have been aging at a fast pace as it has been estimated that low- and middle-income countries contain $69 \%$ of the global population aged more than 60 years [13, 65]. Developing countries have noticeably more older people than the high-income countries, with the more than 70 years population being 1.8 times higher and the more than 60 years population 2.4 times higher than in high-income countries [64]. Therefore, age does not appear to be the reason behind the low shares of countries with a lower HDI in the global mortality of COVID-19.

To the best of our knowledge, the correlation between heterogeneity in healthcare and economic resources and COVID-19 related outcomes has been generally overlooked. A positive association has been reported in mainland China [66] and in Italy [67]. Lippi and colleagues found Spearman's correlation coefficient of $r=0.53$ between gross domestic product at current prices per inhabitant and toll of deaths in the 21 Italian regions and provinces. We have further expanded these analyses at the global level, both for COVID-19 infection incidence and mortality rates.

The current analysis is still preliminary because data about several confounders are lacking. We did not account for comorbidities, Bacillus CalmetteGuérin (BCG) vaccination status, or air quality. Comorbidities have been shown to increase the mortality of COVID-19 [68]. A recent global metaanalysis identified hypertension, respiratory system disease, and cardiovascular disease as risk factors for severe COVID-19 [69]. However, this covariate is unlikely to explain the increased mortality in countries with a high HDI, as comorbidities are very common in the developing world. A recent WHO report revealed that of 1.1 billion persons with hypertension, almost two-thirds reside in developing countries [70]. Moreover, the prevalence of diabetes is quickly rising in developing countries [71]. The lack of necessary basic level of health infrastructure in developing countries would entail that several diseases would be left untreated or undertreated, intensifying vulnerability to complications of COVID-19. In this context, it is also worth highlighting evidence inferring the misconception of claiming that low-income countries may be more immune to (or will be somewhat less affected by) the COVID-19 [72]. By excluding the theory of better immunity in developing countries, the analysis of this study elicits pertinent rationale for considering the interactions between the socioeconomic determinants and both the fatality and recovery rates.

A study has proposed that BCG childhood vaccination could partially explain the reduced morbidity and mortality of COVID-19 in some countries [73, 74], as it could decrease childhood mortality due to a decrease in sepsis and respiratory infections [75]. Several mechanisms have been proposed, including that BCG might cause long-term activation of innate immune cells [76]. The investigators reported that countries that do not have a policy of universal BCG vaccination (e.g., Italy and the USA) were more severely affected by COVID-19 than countries with universal and long-standing BCG policies (e.g., South Korea and Japan) [73]. However, this evidence is still not concrete, and more data are needed. Previous studies have revealed that the effects of BCG on monocytes last only for several months [77], questioning the duration of the immunity following BCG vaccination. Several studies are currently ongoing to determine the effect of BCG vaccination on COVID19 outcome.

Another factor proposed by several publications was the air quality index, which correlated to the number of cases and deaths from COVID-19 [19-22]. These studies concluded that a small increase in longterm average exposure to fine particulate matter leads 
to a substantial increase in the spread and mortality rate of COVID-19.

The possibility that our results may reflect differences in the timing and nature of the country's response (such as testing, case-tracking, isolation, and social distancing measures) to the COVID-19 outbreak cannot be ruled out [32]. It is also possible that countries with a lower HDI are at an earlier stage of the pandemic compared to high HDI countries. However, this explanation is unlikely as the disease has been around for three months, and it seems to have spread to almost every country in the world at this point [54]. Moreover, the lower HDI countries are expected to be less successful in the containment of the contagion [54].

Finally, the difference in mortality between the higher HDI countries and the lower HDI countries may be related to the adequacy of measurement and reporting of cases. A systematic review of studies that assessed the reliability of hospital data on the cause of death revealed that most of the selected studies reported a substantial misdiagnosis of causes of death in hospitals.[77] Additionally, current evidence indicates that COVID-19 deaths are being misattributed to other causes of death, particularly when death occurs at home [78]. According to a recent estimate, the death toll from COVID-19 in selected 14 countries may be $60 \%$ higher than reported in official counts [79]. The accuracy of official death statistics related to COVDI-19 is limited by how efficiently a country is testing people to confirm cases. It possible that countries with a lower HDI are not reporting the exact cause of death due to limited resources to diagnosed COVID-19 infection. For example, in Ecuador's Guayas province, the reported official COVID-19 related deaths between 1 March and 15 April were 245; however, data on total deaths during the same period showed an increase of 350\% [79].

Our study has two main limitations. First, our analyses were based on the first few months of the pandemic, and this needs to be revisited regularly throughout the pandemic phases. Second, as with all cross-country analyses, the potential exists for spurious statistical association produced by unmeasured and unknown confounding factors in the form of ecological fallacy [80-82]. Consequently, the associations observed at the country level may not reflect individual-level associations [83, 84]. The best guide we will have for the effects of pandemics on recovery and mortality rates of a future coronavirus are the studies of the previous epidemics. Therefore, in this preliminary ecological analysis, our attention is turned to the role of socioeconomic determinants in the pandemic COVID-19 recovery and mortality rates.

Unlike other studies that addressed the association of COVID-19 detection with individual social or economic variables, our study examined the association of COVID-19 outcomes with a valid and reliable composite of socioeconomic factors. It provided useful insight into explaining between-country variation in COVID-19 outcomes. To the best of our knowledge, our study is the first study to address the association of HDI and COVID-19 outcomes. Furthermore, the validity of the ecologic-effect estimate was enhanced by controlling for the available known confounders (gender and age). Further work is needed to fully understand the mechanisms by which HDI may have affected COVID-19 recovery and mortality rates.

In conclusion, the HDI is associated with the recovery rate, which is perhaps reflective of the levels of preparedness for pandemics. The positive association between the HDI and mortality rates may point to vulnerabilities in approaches to tackle health crises; this should be further investigated. Further research, using data from various phases of the pandemic and various strategies used including vaccination is need.

\section{Acknowledgments}

The authors have no acknowledgments. There is no funding for this study.

\section{Author contributions}

CONCEPTION: Haitham Jahrami and Amer AlDerazi

METHODOLOGY: Haitham Jahrami and Nicola Luigi Bragazzi

DATA COLLECTION: Haitham Jahrami, Amer AlDerazi and Nicola Luigi Bragazzi

INTERPRETATION OR ANALYSIS OF DATA: Haitham Jahrami, Ahmed S. BaHammam and Randah R. Hamadeh

PREPARATION OF THE MANUSCRIPT: Haitham Jahrami, Amer AlDerazi, Ahmed S. BaHammam, Randah R. Hamadeh and Mohamed Buheji

REVISION FOR IMPORTANT INTELLECTUAL CONTENT: Mohamed Buheji, Dunya, Ahmed and Ahmed Ebrahim

SUPERVISION: Mohamed Buheji and Haitham Jahrami 


\section{Conflict of interest}

All authors have no conflict of interest to declare.

\section{Ethical considerations}

This is an ecologic study of online available data. Therefore, ethical approval was waived.

\section{References}

[1] Guan WJ, Ni ZY, Hu Y, Liang WH, Ou CQ, He JX, et al. Clinical Characteristics of Coronavirus Disease 2019 in China. The New England Journal of Medicine. 2020. doi: 10.1056/NEJMoa2002032.

[2] Kovacevic M, Jahic A. COVID-19 AND HUMAN DEVELOPMENT. Exploring Global Preparedness and Vulnerability. 2020.

[3] Khan S, Siddique R, Shereen MA, Ali A, Liu J, Bai Q, et al. Emergence of a Novel Coronavirus, Severe Acute Respiratory Syndrome Coronavirus 2: Biology and Therapeutic Options. Journal of Clinical Microbiology. 2020;58(5). doi: 10.1128/JCM.00187-20.

[4] Deshwal VK. COVID 19: A Comparative Study of Asian, European, American continent. 2020.

[5] Ebrahim AH, Dhahi A, Husain MA, Jahrami H. The Psychological Wellbeing of University Students Amidst COVID-19 Pandemic: A scoping review, systematic review and a meta-analysis. Sultan Qaboos University Medical Journal [SQUMJ]. 2021;1(1). doi: 10.18295/squmj.6.2021.081.

[6] Wadhera RK, Wadhera P, Gaba P, Figueroa JF, Joynt Maddox KE, Yeh RW, et al. Variation in COVID-19 Hospitalizations and Deaths Across New York City Boroughs. JAMA. 2020. doi: 10.1001/jama.2020.7197.

[7] Webb Hooper M, Nápoles AM, Pérez-Stable EJ. COVID-19 and Racial/Ethnic Disparities. JAMA. 2020. doi: 10.1001/ jama.2020.8598.

[8] Raifman MA, Raifman JR. Disparities in the Population at Risk of Severe Illness From COVID-19 by Race/Ethnicity and Income. American Journal of Preventive Medicine. 2020. doi: 10.1016/j.amepre.2020.04.003.

[9] Vardavas C, Nikitara K. COVID-19 and smoking: A systematic review of the evidence. Tobacco Induced Diseases. 2020;18(March). doi: 10.18332/tid/119324.

[10] Zhao Q, Meng M, Kumar R, Wu Y, Huang J, Lian N, et al. The impact of COPD and smoking history on the severity of COVID-19: A systemic review and meta-analysis. Journal of Medical Virology. 2020. doi: 10.1002/jmv.25889.

[11] Grant WB, Lahore H, McDonnell SL, Baggerly CA, French $\mathrm{CB}$, Aliano JL, et al. Evidence that Vitamin D Supplementation Could Reduce Risk of Influenza and COVID-19 Infections and Deaths. Nutrients. 2020;12(4):988. doi: 10.3390/nu12040988.

[12] Ilie PC, Stefanescu S, Smith L. The role of vitamin D in the prevention of coronavirus disease 2019 infection and mortality. Aging Clinical and Experimental Research. 2020. doi: 10.1007/s40520-020-01570-8.
[13] Lloyd-Sherlock P, Ebrahim S, Geffen L, McKee M. Bearing the brunt of covid-19: older people in low and middle income countries. BMJ. 2020:m1052. doi: 10.1136/ bmj.m1052.

[14] Zhou F, Yu T, Du R, Fan G, Liu Y, Liu Z, et al. Clinical course and risk factors for mortality of adult inpatients with COVID-19 in Wuhan, China: a retrospective cohort study. The Lancet. 2020;395(10229):1054-62. doi: 10.1016/ s0140-6736(20)30566-3.

[15] Berlin I, Thomas D, Le Faou A-L, Cornuz J. COVID-19 and Smoking. Nicotine \& Tobacco Research. 2020. doi: 10.1093/ntr/ntaa059.

[16] Sobral MFF, Duarte GB, da Penha Sobral AIG, Marinho MLM, de Souza Melo A. Association between climate variables and global transmission oF SARS-CoV-2. Science of The Total Environment. 2020;729:138997. doi: https:// doi.org/10.1016/j.scitotenv.2020.138997

[17] Bashir MF, Ma B, Bilal, Komal B, Bashir MA, Tan D, et al. Correlation between climate indicators and COVID-19 pandemic in New York, USA. Science of The Total Environment. 2020;728:138835. doi: https://doi.org/10.1016/ j.scitotenv.2020.138835

[18] Qi H, Xiao S, Shi R, Ward MP, Chen Y, Tu W, et al. COVID-19 transmission in Mainland China is associated with temperature and humidity: A time-series analysis. Science of The Total Environment. 2020;728:138778. doi: https://doi.org/10.1016/j.scitotenv.2020.138778

[19] Coccia M. Factors determining the diffusion of COVID19 and suggested strategy to prevent future accelerated viral infectivity similar to COVID. Science of The Total Environment. 2020;729:138474. doi: https://doi.org/ 10.1016/j.scitotenv.2020.138474

[20] Wu X, Nethery R, Sabath B, Braun D, Dominici F. Exposure to air pollution and COVID-19 mortality in the United States: A nationwide cross-sectional study. medRxiv; 2020.

[21] Travaglio M, Yu Y, Popovic R, Leal NS, Martins LM. Links between air pollution and COVID-19 in England. medRxiv. 2020:2020.04.16.20067405. doi: 10.1101/ 2020.04.16.20067405.

[22] Setti L, Passarini F, De Gennaro G, Barbieri P, Perrone MG, Piazzalunga A, et al. The Potential role of Particulate Matter in the Spreading of COVID-19 in Northern Italy: First Evidence-based Research Hypotheses. medRxiv. 2020: 2020.04.11.20061713. doi: 10.1101/2020.04.11.20061713.

[23] Rocklöv J, Sjödin H. High population densities catalyse the spread of COVID-19. Journal of Travel Medicine. 2020; 27(3). doi: 10.1093/jtm/taaa038.

[24] Zheng R, Xu Y, Wang W, Ning G, Bi Y. Spatial transmission of COVID-19 via public and private transportation in China. Travel Medicine and Infectious Disease. 2020;34:101626. doi: 10.1016/j.tmaid.2020.101626.

[25] Zhao S, Zhuang Z, Cao P, Ran J, Gao D, Lou Y, et al. Quantifying the association between domestic travel and the exportation of novel coronavirus (2019-nCoV) cases from Wuhan, China in 2020: a correlational analysis. Journal of Travel Medicine. 2020;27(2). doi: 10.1093/jtm/taaa022.

[26] Kraemer MUG, Yang C-H, Gutierrez B, Wu C-H, Klein B, Pigott DM, et al. The effect of human mobility and control measures on the COVID-19 epidemic in China. Science. 2020;368(6490):493-7. doi: 10.1126/science.abb4218.

[27] Rhodes JM, Subramanian S, Laird E, Kenny RA. Editorial: low population mortality from COVID-19 in countries 
south of latitude 35 degrees North supports vitamin D as a factor determining severity. Alimentary Pharmacology \& Therapeutics. 2020;51(12):1434-7. doi: 10.1111/apt.15777.

[28] Pan A, Liu L, Wang C, Guo H, Hao X, Wang Q, et al. Association of Public Health Interventions With the Epidemiology of the COVID-19 Outbreak in Wuhan, China. JAMA. 2020; 323(19):1915. doi: 10.1001/jama.2020.6130.

[29] Cohen J, Kupferschmidt K. Countries test tactics in 'war' against COVID-19. Science. 2020;367(6484):1287-8. doi: 10.1126/science.367.6484.1287.

[30] Kenyon C. Why Has COVID-19 Spread More Extensively in Europe than Asia? : MDPI AG; 2020.

[31] Zhao S, Zhuang Z, Ran J, Lin J, Yang G, Yang L, et al. The association between domestic train transportation and novel coronavirus (2019-nCoV) outbreak in China from 2019 to 2020: A data-driven correlational report. Travel Medicine and Infectious Disease. 2020;33:101568. doi: 10.1016/ j.tmaid.2020.101568.

[32] Moquillaza-Alcántara V, Romero-Cerdán A, MunaresGarcía O, Merellano-Navarro E. Variation in the epidemiological indicators of COVID-19 a part of the emergency policies adopted in south american countrie. FapUNIFESP (SciELO); 2020.

[33] Britten R. The Incidence of Epidemic Influenza, 1918-19: A Further Analysis According to Age, Sex, and Color of the Records of Morbidity and Mortality Obtained in Surveys of 12 Localities. Public Health Rep. 1932;47(6):303-75.

[34] Sydenstricker E. The incidence of influenza among persons of different economic status during the epidemic of 1918. 1931. Public health reports (Washington, DC : 1974). 2006; 121 Suppl 1:191-204; discussion 190.

[35] La Ruche G, Tarantola A, Barboza P, Vaillant L, Gueguen J, Gastellu-Etchegorry M, et al. The 2009 pandemic H1N1 influenza and indigenous populations of the Americas and the Pacific. Eurosurveillance. 2009;14(42). doi: 10.2807/ ese.14.42.19366-en.

[36] Schneider MC, Machado G. Environmental and socioeconomic drivers in infectious disease. The Lancet Planetary Health. 2018;2(5):e198-e9. doi: 10.1016/s2542-5196(18) 30069-x.

[37] Buja A, Paganini M, Cocchio S, Scioni M, Rebba V, Baldo V. Demographic and Socio-Economic Factors, and Healthcare Resource Indicators Associated with the Rapid Spread of COVID-19 in Northern Italy: An Ecological Study. medRxiv. 2020:2020.04.25.20078311. doi: 10.1101/ 2020.04.25.20078311.

[38] Whittle RS, Diaz-Artiles A. An ecological study of socioeconomic predictors in detection of COVID-19 cases across neighborhoods in New York City. medRxiv. 2020: 2020.04.17.20069823. doi: 10.1101/2020.04.17.20069823.

[39] House T, Keeling MJ. Household structure and infectious disease transmission. Epidemiology and Infection. 2009; 137(5):654-61. doi: 10.1017/s0950268808001416.

[40] Jaffe R, Ortiz Vera MP, Jaffe K. Globalized low-income countries may experience higher COVID-19 mortality rates. medRxiv. 2020:2020.03.31.20049122. doi: 10.1101/ 2020.03.31.20049122.

[41] Su D, Chen Y, He K, Zhang T, Tan M, Zhang Y, et al. Influence of socio-ecological factors on COVID-19 risk: a cross-sectional study based on 178 countries/regions worldwide. medRxiv. 2020:2020.04.23.20077545. doi: 10.1101/ 2020.04.23.20077545.
[42] Anand S, Sen A. Human Development Index: Methodology and Measurement. In: Sakiko P, editor., 2011.

[43] McGillivray M, White H. Measuring development? The UNDP's human development index. Journal of International Development. 1993;5(2):183-92.

[44] Ivanova I, Arcelus FJ, Srinivasan G. An assessment of the measurement properties of the human development index. Soc indic res. 1999;46(2):157-79.

[45] Martínez-Guido SI, González-Campos JB, Ponce-Ortega JM. Strategic planning to improve the Human Development Index in disenfranchised communities through satisfying food, water and energy needs. Food and Bioproducts Processing. 2019;117:14-29.

[46] Boutayeb A. The burden of communicable and noncommunicable diseases in developing countries. In: Preedy VR, Watson PR, editors. Handbook of Disease Burden and Quality of life Measures. New York, USA: Springer Verlag 2010. p. 532-45.

[47] Morgenstern H. Ecologic Studies in Epidemiology: Concepts, Principles, and Methods. Annual Review of Public Health. 1995;16(1):61-81. doi: 10.1146/annurev.pu.16. 050195.000425 .

[48] Rothman KJ, Greenland S, Lash TL. Modern Epidemiology. 3rd ed. Lippincott Williams \& Wilkins; 2008.

[49] Human Development Index Ranking | Human Development Reports. http://hdr.undp.org/en/content/2019-humandevelopment-index-ranking (2019). Accessed.

[50] Coronavirus Update (Live): COVID-19 Virus Pandemic - Worldometer. https://www.worldometers.info/corona virus/ Accessed 2nd May 2020.

[51] World Population Prospects - Population Division United Nations. https://population.un.org/wpp/Download/ Standard/Population/ Accessed.

[52] Count Regression. Handbook of Regression Analysis. 2012. p. 191-213.

[53] Wijesinghe PR, Ofrin RH, Bhola AK, Inbanathan FY, Bezbaruah S. Pandemic influenza preparedness in the WHO South-East Asia Region: a model for planning regional preparedness for other priority high-threat pathogens. WHO South-East Asia journal of public health. 2020;9(1):43-9.

[54] Bong CL, Brasher C, Chikumba E, McDougall R, MellinOlsen J, Enright A. The COVID-19 Pandemic: Effects on Low and Middle-Income Countries. Anesth Analg. 2020:1. doi: 10.1213/ANE.0000000000004846.

[55] Hopman J, Allegranzi B, Mehtar S. Managing COVID-19 in Low- and Middle-Income Countries. JAMA. 2020;323(16): 1549. doi: 10.1001/jama.2020.4169.

[56] Gilbert M, Pullano G, Pinotti F, Valdano E, Poletto C, Boëlle $\mathrm{P}-\mathrm{Y}$, et al. Preparedness and vulnerability of African countries against importations of COVID-19: a modelling study. The Lancet. 2020;395(10227):871-7. doi: 10.1016/s01406736(20)30411-6.

[57] Dahab M, van Zandvoort K, Flasche S, Warsame A, Spiegel $\mathrm{PB}$, Waldman RJ, et al. COVID-19 control in low-income settings and displaced populations: what can realistically be done? Health in Humanitarian Crises Centre. 2020.

[58] Malelelo-Ndou H, Ramathuba DU, Netshisaulu KG. Challenges experienced by health care professionals working in resource-poor intensive care settings in the Limpopo province of South Africa. Curationis. 2019;42(1). doi: 10.4102/curationis.v42i1.1921. 
[59] Murthy S, Leligdowicz A, Adhikari NKJ. Intensive Care Unit Capacity in Low-Income Countries: A Systematic Review. PLOS ONE. 2015;10(1):e0116949. doi: 10.1371/ journal.pone.0116949.

[60] Anderson RM, Heesterbeek H, Klinkenberg D, Hollingsworth TD. How will country-based mitigation measures influence the course of the COVID-19 epidemic? The Lancet. 2020;395(10228):931-4. doi: 10.1016/S01406736(20)30567-5

[61] Verity R, Okell LC, Dorigatti I, Winskill P, Whittaker C, Imai $\mathrm{N}$, et al. Estimates of the severity of coronavirus disease 2019: a model-based analysis. Lancet. 2020:1-9 (Ahead-ofprint) https://doi.org/10.1016/S473-3099(20)30243-7

[62] Dietz W, Santos-Burgoa C. Obesity and its Implications for COVID-19 Mortality. Obesity (Silver Spring). 2020. doi: 10.1002/oby.22818.

[63] BaHammam AS, Bindayna KM, Joji RM, Jahrami H, Faris MAE, Bragazzi NL. Outcomes of COVID-19 in the Eastern Mediterranean Region in the first 4 months of the pandemic. Saudi Med J. 2020;41(9):907-15. doi: 10.15537/ smj.2020.9.25320.

[64] Schellekens P, Sourrouille D. Tracking COVID-19 as cause of death: global estimates of relative severity. 2020.

[65] United Nations, Department of Economic and Social AffairsPopulation Division, Population Division (2019), editor. World Population Ageing 2019: Highlights. United Nations; 2019.

[66] Ji Y, Ma Z, Peppelenbosch MP, Pan Q. Potential association between COVID-19 mortality and health-care resource availability. Lancet Glob Health. 2020;8(4):e480. doi: 10.1016/s2214-109x(20)30068-1.

[67] Lippi G, Henry B, Mattiuzzi C, Bovo C. The death rate for COVID-19 is positively associated with gross domestic products. Acta bio-medica: Atenei Parmensis. 2020;91. doi: 10.23750/abm.v91i2.9514.

[68] Guan WJ, Liang WH, Zhao Y, Liang HR, Chen ZS, Li YM, et al. Comorbidity and its impact on 1590 patients with Covid-19 in China: A Nationwide Analysis. Eur Respir J. 2020. doi: 10.1183/13993003.00547-2020.

[69] Yang J, Zheng Y, Gou X, Pu K, Chen Z, Guo Q, et al. Prevalence of comorbidities and its effects in coronavirus disease 2019 patients: A systematic review and meta-analysis. Int J Infect Dis. 2020;94:91-5. doi: 10.1016/j.ijid.2020.03.017.

[70] World Healrh Organization: Hypertension: Fact Sheet. https://www.who.int/news-room/fact-sheets/detail/hyper tension (2019). Accessed.
[71] World Healrh Organization. Global report on diabetes. Geneva, Switzerland: World Health Organization; 2016.

[72] Roy S. Low-income countries are more immune to COVID19: A misconception. Indian J Med Sci. 2020;72(1):5-7. doi: 10.25259/IJMS_26_2020.

[73] Miller A, Reandelar MJ, Fasciglione K, Roumenova V, Li Y, Otazu GH. Correlation between universal BCG vaccination policy and reduced morbidity and mortality for COVID19: an epidemiological study. Preprint at medRxiv. 2020: https://doi.org/10.1101/2020.03.24.20042937

[74] Berg M, Yu Q, Salvador C, Melani I, Kitayama S. Mandated Bacillus Calmette-Guérin (BCG) vaccination predicts flattened curves for the spread of COVID-19. medRxiv; 2020.

[75] Hollm-Delgado MG, Stuart EA, Black RE. Acute lower respiratory infection among Bacille Calmette-Guerin (BCG)-vaccinated children. Pediatrics. 2014;133(1):e7381. doi: 10.1542/peds.2013-2218.

[76] Redelman-Sidi G. Could BCG be used to protect against COVID-19? Nat Rev Urol. 2020. doi: 10.1038/s41585-0200325-9.

[77] Kleinnijenhuis J, Quintin J, Preijers F, Benn CS, Joosten LA, Jacobs C, et al. Long-lasting effects of BCG vaccination on both heterologous Th1/Th17 responses and innate trained immunity. J Innate Immun. 2014;6(2):152-8. doi: 10.1159/ 000355628 .

[78] Economist T. Deaths from Cardiac Arrests Have Surged in New York City. The Economist 2020.

[79] Burn-Murdoch J, Romei V, Giles C. Global coronavirus death toll could be $60 \%$ higher than reported. Financial Times. 2020.

[80] Greenland S, Morgenstern H. Ecological Bias, Confounding, and Effect Modification. International Journal of Epidemiology. 1989;18(1):269-74. doi: 10.1093/ije/18.1. 269.

[81] Pearce N. The ecological fallacy strikes back. Journal of Epidemiology \& Community Health. 2000;54(5):326-7. doi: 10.1136/jech.54.5.326.

[82] Saunders C, Abel G. Ecological studies: use with caution. British Journal of General Practice. 2014;64(619):65-6. doi: 10.3399/bjgp14x676979.

[83] Morgenstern H. Uses of ecologic analysis in epidemiologic research. American Journal of Public Health. 1982;72(12): 1336-44. doi: 10.2105/ajph.72.12.1336.

[84] Grimes DA, Schulz KF. Descriptive studies: what they can and cannot do. Lancet (London, England). 2002;359(9301): 145-9. doi: 10.1016/s0140-6736(02)07373-7. 